\title{
FACTORS CONTRIBUTING TO TRAFFIC FLOW CONGESTION IN HETEROGENOUS TRAFFIC CONDITIONS
}

\author{
John Mahona ${ }^{1}$, Cuthbert Mhilu' ${ }^{2}$, Joseph Kihedu ${ }^{3}$, Hannibal Bwire ${ }^{4}$ \\ ${ }^{1}$ Department of Transport Engineering and Technology, National Institute of Transport, P.O.BOX 705, \\ Dar es Salaam, Tanzania \\ 2,3 Department of Mechanical Engineering and Industrial, Collège of Engineering and Technology, \\ University of Dar es Salaam, P.O.BOX 35131 Tanzania \\ ${ }^{4}$ Department of Transportation and Geotechnical Engineering, Collège of Engineering and Technology, \\ University of Dar es Salaam, P.O.BOX 35131 Tanzania
}

Received 14 March 2019; accepted 15May 2019

\begin{abstract}
Most of the urban roadways do experience traffic flow congestion at various road sections called critical traffic points, which is partly contributed by the presence of various factors on the roadways. A number of studies have used travel time indices to determine congested links of the road networks. However, the travel time-delay based indices have found less application in the identification and quantification of congestion levels in the road networks. As a result, a limited number of studies have examined the factors contributing to the propagation of congestions at various road sections using the travel time-delay indices. This paper aims to identify factors contributing to propagation of traffic congestions at frequently congested traffic critical points and to estimate their influence on the entire road network using travel time-delay data. Travel time-delay data were collected by using test moving cars. The results indicate that low travel-delay transition index below 0.70 signify the jam and crowded traffic flow condition, while higher values greater than 0.70 indicate free flow phenomena. On the other hand, high congestion index values indicate jam and crowded flow conditions whereas the low values below 0.5 signify free flow conditions. Further, the results showed that low transition index and high congestion index values were associated with roadway design factors such as T-joints, cross joints, bus stops, humps and traffic lights, which are considered to be static bottlenecks which impedes the vehicle flow.
\end{abstract}

Keywords: congestion, travel time-delay, transition index, congestion index, Critical Traffic Points.

\section{Introduction}

Traffic congestion has become a serious problem in many cities of developing countries as most of their Central Business Districts (CBD) are located in the city centers (Chauhan et al., 2017; Kumar and Sivanandan, 2017). Motorized traffic movements in major cities of developing countries exhibit heterogeneous traffic conditions. Congestion around urban roadway stretches are found at the salient locations called the critical traffic points (CTPs) where congestion is settled (Chauhan et al., 2017).

Measures of congestion are intended to evaluate the performance of the road network

${ }^{1}$ Corresponding author: john.mahona@nit.ac.com 
and to diagnose problem areas. They provide information on how well the roadway has met certain stated goals and targets and can also help to explain variations in user experiences of the road network together with their influencing feeder roads ( $\mathrm{He}$ et al., 2016; Wen et_al., 2014; Rao and Rao, 2016). Currently, there is no accepted set of congestion measures to be used by all transportation professionals or agencies to monitor road network traffic conditions. As a result, there is a need for reliable congestion measures that can be applied to urban roads and be understood by the general public (Wang et al., 2014; Xu et al., 2016).

Generally, the categories of congestion measures that are commonly employed include user-based perspectives like delays, average speed and travel time; measures that analyze how well the system is functioning at a given location like the volume-tocapacity (V/C) ratio, which is usually expressed as a level-of-service (LOS) category; spatial-based measures like queue length, queue density, and vehicle miles traveled; measures of travel time reliability and the number of times a vehicle stops because of congested conditions i.e., travel time-delay (Xu et al., 2016). Travel time is an important measure in quality analysis of urban road network comprising of various problematic links and points that are influenced by their feeder roads (Xu et al., 2016; He et al., 2016). Most of the previous studies employed travel time indices to evaluate road network performance based on the influences of a particular factor such as weather conditions, traffic incidences and intersections. These studies used single evaluation indicator, e.g., travel speed and travel time that can be obtained through various methods such as the loop detector, GPS, video, filed observation and manual recording of travel time-delay (TD) data etc (Chauhan et al., 2017; Wen et al., 2014; Ataiwe et al., 2012). Karuppanagounder and_Muneera (2017) used travel time-based indices to evaluate the performance of the urban road links under heterogenous traffic conditions rather than assessing traffic flow on each critical traffic point in the urban road network. Furthermore, in urban road networks where heterogeneous traffic flow is more profound, various studies have stated that the average time to traverse a kilometer is estimated to be around $\mathbf{1 . 2}$ minutes translating to low posted speed limit ranging from 30 to $60 \mathrm{~km} / \mathrm{hr}$ (Lamotte and Geroliminis, 2017; Fazio et al., 2014; Wen et al.,2014; Deardoff et al., 2011).

However, considering the complexity and dynamic nature of traffic, it is difficult to assess traffic congestion conditions of urban road networks without having a clear view of the flow patterns variation, location as well as the time of occurrence (He et al., 2016; Zhang et al., 2017). Urban traffic pattern is usually measured by vehicle average travel time-delay (TD) which can be translated to the corresponding average travel speed. Travel time-delay (TD) is composed of time in which the means of transport is in motion and time in which the mode of transport is stopped or moving sufficiently slow as to be stopped. This definitely reflects the motorists' behavior on urban road network and changes with the actual matching status of traffic demand and supply (He et al., 2016). Urban traffic problems are further exacerbated by the concentration of most of the working places in the same areas (CBD), so that traffic is essentially uni-directional during the morning and evening peak periods (Kiunsi, 2013). It is this latter problem which results in spatial variation of traffic flow patterns resulting into formation of wide 
range congestions status in urban areas at different location and time.

On the other hand, the use of travel time data knowledge to quantify congestions on links is associated with problems of ignoring the spatial correlation of traffic conditions between links so as to have the general traffic flow conditions of the whole road section under consideration (Lu, 2017; Torrisi et al., 2017). The use of travel time-delay based indices like the TD transition index and congestion index to quantify congestion levels at particular place and time as well as recording the respective flow impeding factors on the links have not been employed by the researchers. In this study, factors contributing to high traffic flow pattern variations were evaluated based on travel time-based indices such as travel time-delay transition index (TD_TI) and congestion index (CI). The TD $\mathrm{TI}$ is the ratio of Free Flow Time (FFT) to the average TD whereas the $\mathrm{CI}$ is the ratio of the difference of TD and the FFT to the FFT. Transition index is the measure on how easy vehicles can traverse through a certain CTP with minimum impedance effects. The low index values signify high impedance effect and thus resulting into traffic congestion whereas the high values indicate free flow.

In this regard, the study aims to examine the spatial aspects of traffic state variation patterns at various critical traffic points (CTPs) on urban road sections in a developing country city of Dar es salaam through the use of travel time-delay transition index (TD_TI) and congestion index (CI). The performance of any of these critical traffic points (CTPs) determines the performance of nearby elements finally enabling the estimation of status of traffic flow of the whole network. Thus, the study reveals the factors responsible for causing the traffic pattern variations leading to either propagation or non- propagation of congestions at particular time and place.

\section{Methods and Materials}

\subsection{Description of Study Area and Methods}

The method used in this study is based on study area where data collection was made in step-by-step approach followed by analysis of Travel time-Delay (TD) data by translating into Travel time-Delay Transition Index (TD_TI) and congestion index (CI). The identified study area was made from suitable routes in Dar es Salaam urban road network in Tanzania that includes substantial sections of both arterial and subarterial roads and which are often wrought with recurring congestion. Dar es Salaam, which until recently was capital city of Tanzania has remained to be the economic hub of the country. The road network map of Dar es Salaam city (Figure 1) was used for identification of the studied road network. As such, the daily intra-urban movements to work, recreational centers, markets, shops and schools are becoming more and more difficult and are characterized by discomfort, delays, waste of time, energy and resources. This problem is attributed the fact that most of the government offices and private organizations are located within the central business district (CBD), while the persons that work in these establishments are residents within the peripheries. This implies that they have to travel to the CBD daily in the morning and return in the 
evening resulting to morning and evening peak periods within the city. The situation leads to the formations of long vehicle queues due to huge traffic flow pattern variations at certain critical traffic points (CTPs) resulting to reduction of the effective accessibility of residents, activities and jobs thus loss of opportunities for both the public and business.

The following set criteria were taken onboard: the one which spans from Dar es Salaam sub-urban areas (peripheries) into the Central Business District (CBD) and vice versa were given first priority, the road network must include at least ten critical traffic points (CTPs) and that all CTPs must not include the new development to facilitate smooth traffic flow like construction of flyover, high occupancy lanes like special lanes for public buses etc. Again, the length of the network must be long enough to have sufficient collector street purposely to have substantive traffic volumes. The selected road networks are a typical representation of urban routes in Dar es Salaam comprising road links of different categories like major arterials and collector streets with varying geometrics and volume levels. The chosen road networks include Bagamoyo, Kawawa and Nyerere road. All these road network include various links and salient points known as the critical traffic points where the recurrent traffic congestions are settled. It is interesting however, that Nyerere road has been included only because it is the only one that joins several peripheries towards the CBD together with those coming from the airport terminal in the city despite having the particular feature of flyover construction.

A reconnaissance survey on the study area were carried out at the selected road sections to identify and locate the critical traffic points (CTPs): a point where large traffic flow pattern variations was noticed translating to slow traffic flow movement and thus prompting the occurrence of recurring traffic congestion at the particular place and time. To identify and locate these locations, physical observations conducted on weekly basis using public, private and motorcycles by driving through all chosen road networks. While driving, an observer records employing the stop watch and the tally sheet the location name and time as well as the travel direction (inbound or outbound) when there is existence of congestion or not. While conducting this exercise it was important to identify the peak periods (time slots) during which the important traffic flow patterns would be recorded. Subsequently these road networks were divided into segments termed as the Critical Traffic Points (CTPs) and for this purpose, several CTPs were chosen (Fig. 1.). Most of them comprised several observed bottlenecks (flow impeding factors) such as bus stops, humps, T-junctions, cross junctions, traffic light points and major intersections. The selected road networks and respective stretches (CTPS) are a typical representation of urban routes in Dar es Salaam comprising road links of different categories like major arterials and feeder streets with varying geometrics and volume levels. 


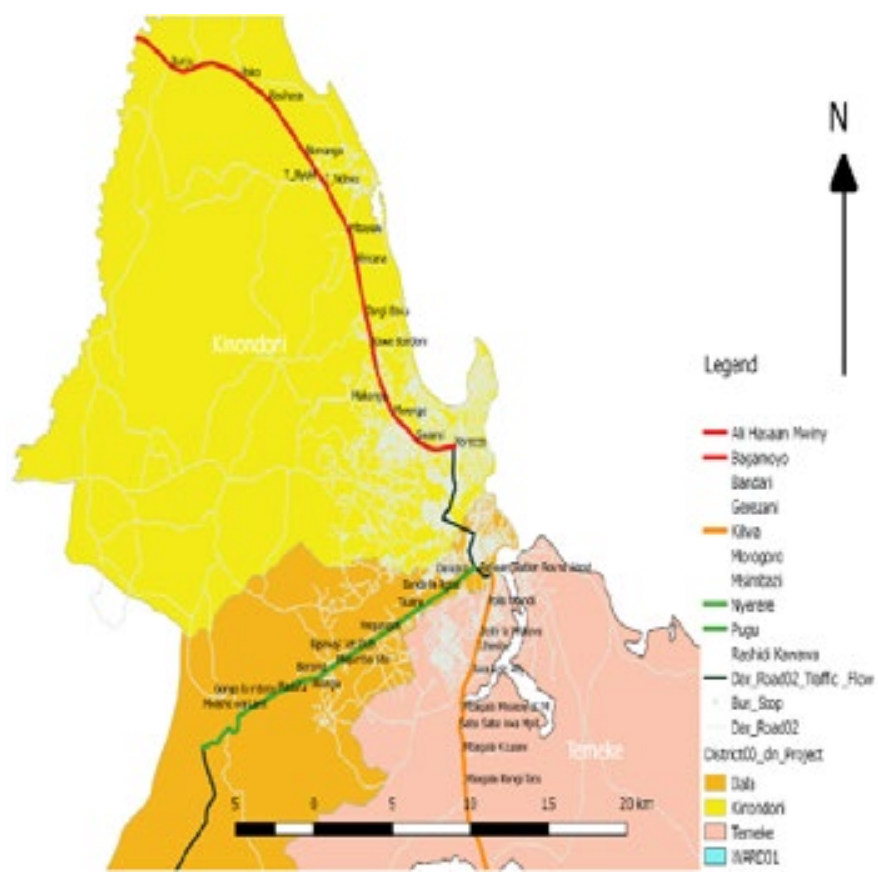

Fig. 1.

Dar es Salaam City Roads Indicating the Studied Road Networks with Their Respective CTP's Source: Adapted from the Google Map of the study area (2017)

The next step was the identification of potential time slots purposely to devise various traffic types at respective time slots (Table 1). During this exercise two major time slots indicating the travel direction were observed in which the higher and moderate traffic flow patterns are frequently observed: Inbound (comprising morning peak and morning non-peak) and Outbound (comprising evening peak and evening nonpeak) with their time variations as indicated in Table 1.

\section{Table 1}

Showing Observation of Traffic Type, Time Slots and Travel Direction

\begin{tabular}{|c|c|c|c|}
\hline \multirow{2}{*}{ Traffic Type } & \multicolumn{2}{|c|}{ Time Slot (Hours) } & \multirow{2}{*}{ Travel Direction } \\
\cline { 2 - 3 } & Start & End & \multirow{2}{*}{ INBOUND (Towards CBD) } \\
\hline Morning peak & 05.30 & 10.00 & \\
\hline Morning non-peak & 10.00 & 16.00 & \multirow{2}{*}{ OUTBOUND (From CBD) } \\
\hline Evening peak & 16.00 & 21.00 & \\
\hline Evening non-peak & 21.00 & 05.30 & \\
\hline
\end{tabular}




\subsection{Data Types and Collection}

Most of the data of this work were collected from primary source. Nevertheless, a significant amount of information regarding the work were also collected from secondary sources. However, for primary data relating to traffic survey, the following were emphasized: Identification of urban road network to be studied; Identification of critical traffic points on all selected urban road networks and their associated vehicle flow impeding factors (bottlenecks); Travel time-delay (TD) and Link length. Data collection primarily involved traffic parameter observation of factors at various road network locations
(CTPs) causing major traffic flow dynamics leading to traffic congestions (Table 2). Immediately after these observations, the travel time-delay survey was conducted using the test moving car method involving the stop watch, note pad and the traffic tally sheets. The data were collected in a minimum of three runs for each time slot in a count period of 45 minutes for sixteen (16) weeks during August, September, October and November 2017. For each road section studied, data was collected on the city bound (inbound) and outward-bound directions (outbound). The designated time slot/frame is as shown in Table 1 were fixed for data collection with the associated traffic flow impeding factors.

Table 2

Showing Observation of Traffic Type, Time Slots and Travel Direction

\begin{tabular}{|c|c|c|c|c|c|}
\hline \multicolumn{2}{|c|}{ Bagamoyo Road } & Nyerere Road & & Kawawa Road & \\
\hline Location/ CTPs & Factors & Location/ CTPs & Factors & Location/CTPs & Factors \\
\hline Bunju & & Mwisho wa lami & & Mbagala Rangi Tatu & \\
\hline Boko & \multirow{2}{*}{ B1, B2 } & Gongo la Mboto & $\mathrm{B} 2, \mathrm{~B} 4, \mathrm{~B} 5$ & Mbagala Kizuiani & $\mathrm{B} 1, \mathrm{~B} 2$ \\
\hline Basihaya & & Madafu & $\mathrm{B} 1, \mathrm{~B} 2, \mathrm{~B} 4$ & Saba Saba kwa Mpili & \\
\hline Namanga & $\mathrm{B} 1, \mathrm{~B} 2$ & Ukonga & $\mathrm{B} 1, \mathrm{~B} 2, \mathrm{~B} 3, \mathrm{~B} 8$ & Mbagala mission/ KTM & $\mathrm{B} 1, \mathrm{~B} 2, \mathrm{~B} 8$ \\
\hline Tegeta Nyuki & $\mathrm{B} 1, \mathrm{~B} 2, \mathrm{~B} 4$ & Banana & $\mathrm{B} 1, \mathrm{~B} 2, \mathrm{~B} 4, \mathrm{~B} 3$ & Mtongani & B1, B4, B5 \\
\hline Tegeta Ndevu & B4 & Majumba sita & B1, B2 B3, B4 & Kwa Azizi Ally & B1, B2 \\
\hline Mbuyuni & $\mathrm{B} 1, \mathrm{~B} 2, \mathrm{~B} 4$ & Kipawa/ jet club & $\mathrm{B} 1, \mathrm{~B} 2, \mathrm{~B} 3, \mathrm{~B} 4$ & Saba Saba & $\mathrm{B} 1, \mathrm{~B} 2$ \\
\hline Africana & \multirow{4}{*}{$\begin{array}{l}\text { B1, B2, B3, } \\
\text { B4, B5, B7 }\end{array}$} & Vingunguti & $\mathrm{B} 1, \mathrm{~B} 2, \mathrm{~B} 4, \mathrm{~B} 8$ & Uhasibu & B1, B2, B4 \\
\hline Tangi bovu & & Tazara & B2, B4, B5, B9 & Salvation Army & $\mathrm{B} 1, \mathrm{~B} 2$ \\
\hline Kawe Bondeni & & Banda la ngozi & B1, B2 & Police Ufundi & $\mathrm{B} 1, \mathrm{~B} 8$ \\
\hline Makongo & & Darajani & $\mathrm{B} 1, \mathrm{~B} 2, \mathrm{~B} 4$ & Bandari & $\mathrm{B} 3, \mathrm{~B} 8$ \\
\hline Mwenge & B4, B5 & $\begin{array}{c}\text { Bus Station/ } \\
\text { Kamata }\end{array}$ & B2, B4, B5 & $\begin{array}{c}\text { Railway Staion Round } \\
\text { About }\end{array}$ & B5, B2, B8 \\
\hline Sayansi & \multirow{2}{*}{$\begin{array}{l}\text { B1, B2, B4, } \\
\text { B5 }\end{array}$} & Msimbazi Gerezani & $\mathrm{B} 1, \mathrm{~B} 2$ & BRT Gerezani & $\mathrm{B} 1, \mathrm{~B} 2$ \\
\hline Morrocco & & & & & \\
\hline
\end{tabular}

Notes: B1 -T-Junctions; B2 - Bus Stops; B3 - Road Humps; B4 - Traffic Lights; B5 - Cross-Junctions; B6 - Work Zones; B7 - Incidents /accidents; B8 - Road Zebra; B9 - Major New Constructions;

The data were collected for a 4 month's (16 weeks) period and represented in five working days average travel time-Delay (TD): Monday, Tuesday, Wednesday, Thursday and Friday. Variations in travel times during peak periods were taken into account by staggering start times within each peak period to represent fairly conditions over the time period as a whole. During the data collection period, the threshold time 
for travelling on each road network during the free flow regime were conducted and recorded accordingly. Threshold time is the time taken to travel from the origin to the destination of the road network during the free flow regime. The average threshold time in minutes on each inbound and outbound travel direction were observed to be in average of 35.12, 21.42 and 25.96 minutes for Bagamoyo, Kilwa and Nyerere roads respectively (Table 3) and from this table the travel factor minutes is estimated to be about 1.2 minutes per one kilometer it is the estimated time to traverse a distance of one kilometer within the CTPs. These data were described for each road network.

\section{Table 3}

Showing the Threshold Time to Traverse the Road Network at Free Flow Time, the Approximate Length and the Estimated Travel Factor for Each Kilometer in Each Road Network

\begin{tabular}{|c|c|c|c|}
\hline Road Network & Threshold Time & Length, $\mathbf{D}(\mathbf{k m})$ & Travel Factor minutes $/ \mathbf{1 ~ k m}$ \\
\hline Bagamoyo & 35.12 & 30 & $1.17 \mathrm{~min} / \mathrm{km}$ \\
\hline Kilwa & 21.42 & 18 & $1.19 \mathrm{~min} / \mathrm{km}$ \\
\hline Nyerere & 25.96 & 22 & $1.18 \mathrm{~min} / \mathrm{km}$ \\
\hline
\end{tabular}

\subsubsection{Bagamoyo Road}

Figures 2 indicates the TD_TI and FFT variations at each CTPs on Bagamoyo road inbound and outbound travel direction respectively. The higher values signify more problematic locations justifying for propagation of either crowded or jam flow at the respective places and time whereas the low values correspond to less or no traffic flow impedes and hence free flow. During inbound travel direction (the solid lines) several CTPs observed to have higher TD values (above the FFT black dash line) showing that there is higher probability of slow vehicle movement entailing propagations of traffic congestions at the respective locations as well as time. Whereas, during outbound travel direction (dash lines) several CTPs were observed to have higher TD values showing that there is higher observation of slow vehicle movement entailing propagations of traffic congestions at the respective locations as well as time. However, the low values of TD correspond to free flow characteristics.

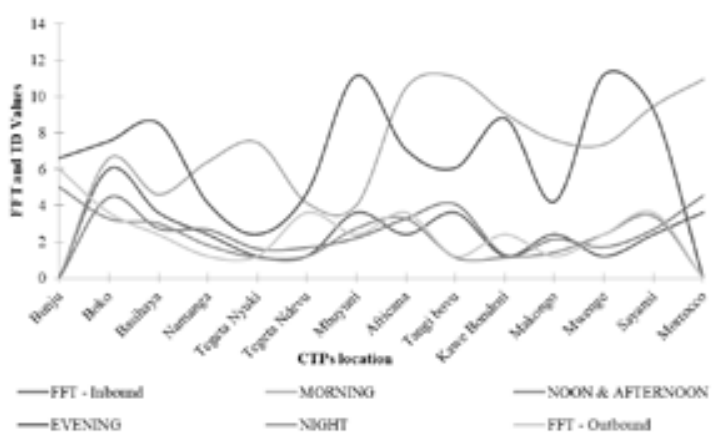

Fig. 2.

The Average Free Flow Time (FFT) and Travel Time-Delay (TD) Data Values Distribution at Various Locations During Inbound and Outbound Travel Directions Along Bagamoyo Road 


\subsubsection{Nyerere Road}

Fig. 3. indicates the TD_TI and FFT variations at each CTPs on Nyerere road inbound and outbound travel direction respectively. The higher values signify more problematic locations justifying propagation of either crowded or jam flow at the respective places and time whereas the low values correspond to free flow.

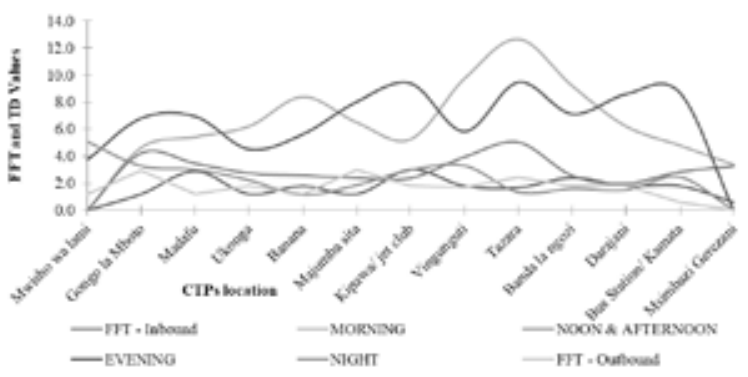

Fig. 3.

The Average Free Flow Time (FFT) and Travel Time-Delay (TD) Data Values Distribution at Various Locations During Inbound and Outbound Travel Directions Along Nyerere Road

\subsubsection{Kilwa Road}

Figure 4 indicates the TD_TI and FFT variations at each CTPs on Kilwa road inbound and outbound travel direction respectively. The higher values signify more problematic locations justifying for propagation of either crowded or jam flow at the respective places and time whereas the low values correspond to less or no free flow phenomena illustrating that the presence of the identified bottlenecks have no significant effect on vehicle flow during the time.

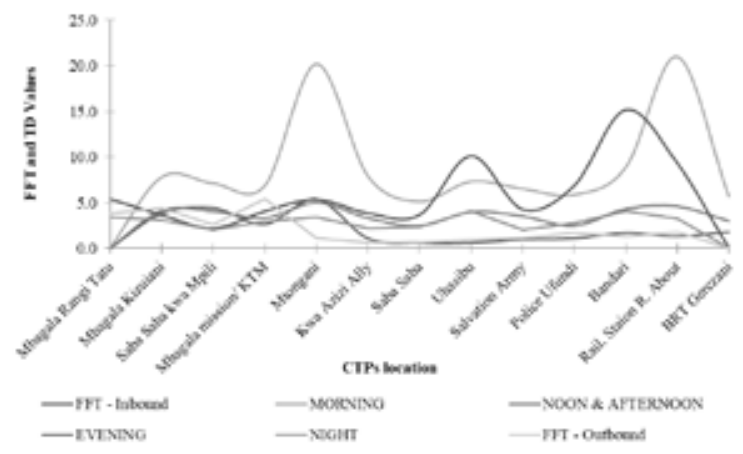

Fig. 4.

The Average Free Flow Time (FFT) and Travel Time-Delay (TD) Data Values Distribution at Various Locations During Inbound and Outbound Travel Directions Along Kilwa Road 


\section{Data Analysis}

\subsection{Travel time Delay Indices-Based Results and Their Variations}

Manually collected data were digitized and comprehensive figures were obtained by converting these data on each road section to the corresponding Travel time-Delay indexes (TD_TI) and Congestion Index (CI) for all time slots and each travel direction (Inbound and outbound) (Figures 3 and 4). The Travel time-Delay (TD) data for sixteen weeks (four months) were averaged to obtain five working days for each time slots (inbound and outbound travel) and then converted to TD_TI values and congestion index (CI). Data were converted to Travel time-Delay Transition Index (TD_TI) and congestion index (CI) results using the following relations:

$T D=\frac{F F T}{T D}$

Where FFT is the observed free flow time at the Critical Traffic Point (CTP) and TD is the respective average travel time-delay (TD) within the CTP.

$$
C I=\frac{(T D-F F T)}{F F T}
$$

$F F T=1.2 \times \mathrm{D}$

Where $\mathrm{D}$ is the distance of the responsible Critical Traffic Point (CTP) and 1.2 minutes is the time in minutes taken to traverse a kilometer termed as the travel factor (Table 3) and also derived from the literature as well as from the average threshold time on each road network divided by the distance of the road network. The Travel time-Delay Transition Index (TD_TI) and congestion index (CI) values were calculated on each road network at respective CTPs and presented in the Figures $3 \mathrm{a}-\mathrm{f}$ and $4 \mathrm{a}-\mathrm{f}$. the TD_TI values variations at each CTPs on each road network are explained as follows. The explanations are governed by the Table 4 which have values tabulated in ranges with their respective interpretations as indicated purposely to allow for data interpretations at various locations and time on the road network.

Table 4

Tabulated Range of Values of TD_TI and CI with Their Interpretations

\begin{tabular}{|c|c|c|c|}
\hline Traffic Flow State & Stabilization of Driving & Remarks of TD_TI Values & Remarks of CI Values \\
\hline Free Flow & Good & $0.70<$ TD_TI & CI $\leq 0.50$ \\
\hline Crowded Flow & Bad $\backslash$-alarming situations & $0.40<$ TD_TI $\leq 0.70$ & $0.50<\mathrm{CI} \leq 1.00$ \\
\hline Jam Flow & Depend on the vehicle on the front & TD_TI $\leq 0.40$ & $1.00<\mathrm{CI}$ \\
\hline
\end{tabular}

\subsubsection{Bagamoyo Road}

The evaluation of the CTPs performances along Bagamoyo road was done by analyzing the variations of TD_TI values at each link. The low values (below 0.7 - a black line) are associated with the jam and crowded vehicle flow characteristics being the result of high traffic flow pattern variations at these CTPs (Figures 5 (a) and (b)). These CTPs are identified to be Namanga, Tegeta Nyuki, Tegeta Ndevu, Africana, Tangi bovu, Kawe Bondeni, Makongo, Mwenge, Sayansi and Makongo during inbound. However, the one observed to indicate high flow pattern variations (low TD_TI values- below 0.7 ) 
during Outbound are the same CTPs except that their values have slight differences. Additionally, some other CTPs shown these problems in terms of jam and crowded flow

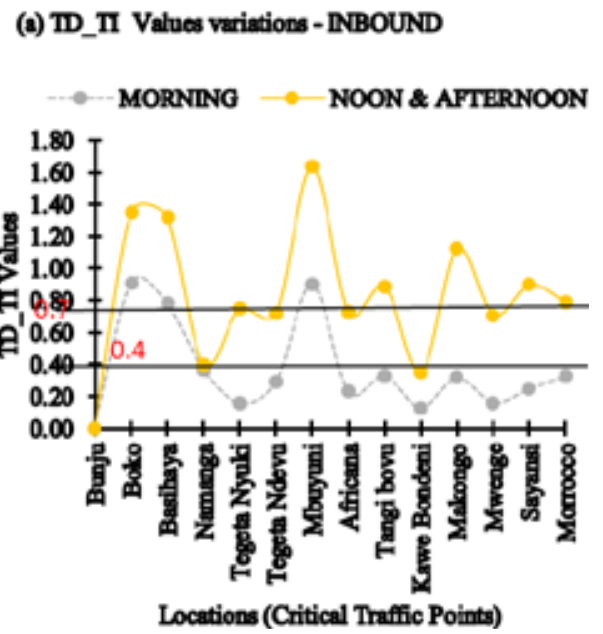

are Basihaya and Boko, but they are caused by the presence of similar road bottlenecks. These require special attention as they do not show problems during inbound.

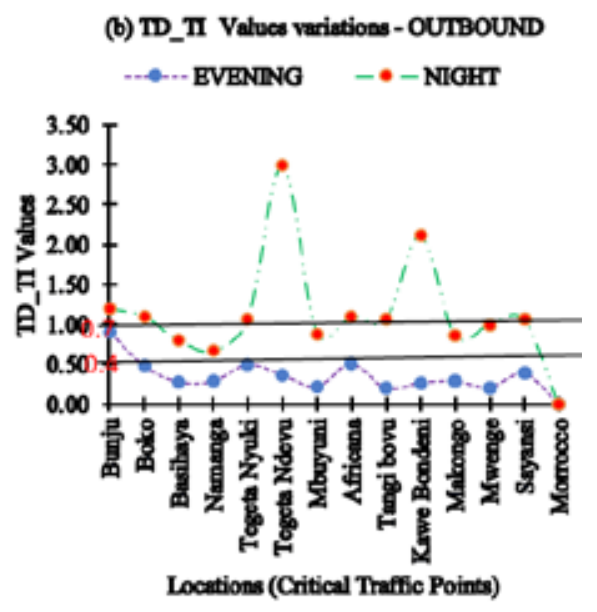

Fig. 5.

The Travel Time-Delay Transition Index ((TD_TI) Values Distributions at Various Critical Traffic Points (Ctps)) (a) Inbound Directions and ( $\bar{b})$ Outbound Directions

Note 1: Black lines (0.4 and 0.7) are drawn to represent the division of distributions.

Note 2:0.00 - TD_TI VALUE means the starting point towards the next road link i.e the direction of travel towards the $C B D$ and vice versa.

For the case of congestion Index (CI) Figure 6 , the higher values ranging from 0.5 and above correspond to jam and crowded flow characteristics. From this Figure the CTPs indicated to have higher CI values are Namanga (1.67), Tegeta Nyuki (5.22), Tegeta Ndevu (2.44), Africana (3.36), Tangi bovu (2.07), Kawe Bondeni (6.56), Makongo (2.17), Mwenge (5.13), Sayansi (2.94) and Makongo (2.04) during inbound. Whereas, during outbound almost the same CTPs are observed to have higher values but with slight differences as shown on the Figure 6.
The CI distributions during noon and afternoon inbound and night outbound, most of the CTPs along Bagamoyo road indicated to have low values below 0.5 signifying free flow characteristics. Whereas, during outbound almost the same CTPs are observed to have higher values but with slight differences as shown on the Figure 6. The CI distributions during noon and afternoon inbound and night outbound, most of the CTPs along Bagamoyo road ranging indicated to have low values below 0.5 signifying free flow characteristics. 


\subsubsection{Nyerere Road}

The evaluation of the CTPs performance along Nyerere road was done by analyzing the variations of TD_TI values at each link (Figure 7 (a) and (b)). From Figure 7(a) the low values (below 0.7 ) are associated with the jam and crowded vehicle flow characteristics being the result of high traffic flow pattern variations at these CTPs. These CTPs are identified to be Gongo la mboto, Madafu, Ukonga, Banana, Majumba Sita, Kipawa/Jet
Club, Vingunguti, Tazara, Banda la Ngozi, Darajani, Railway B/station and Msimbazi Gerazani during inbound. However, the one observed to indicate high flow pattern variations (low TD_TI values below 0.7 ) during Outbound (Figure. 7 (b)) are the same CTPs except that their values have slight differences. Most of the CTPs during noon \& afternoon do not show high traffic flow pattern variations (TD_TI more than 0.70 ) as few vehicles are observed to use road network compared to the morning commuting period.

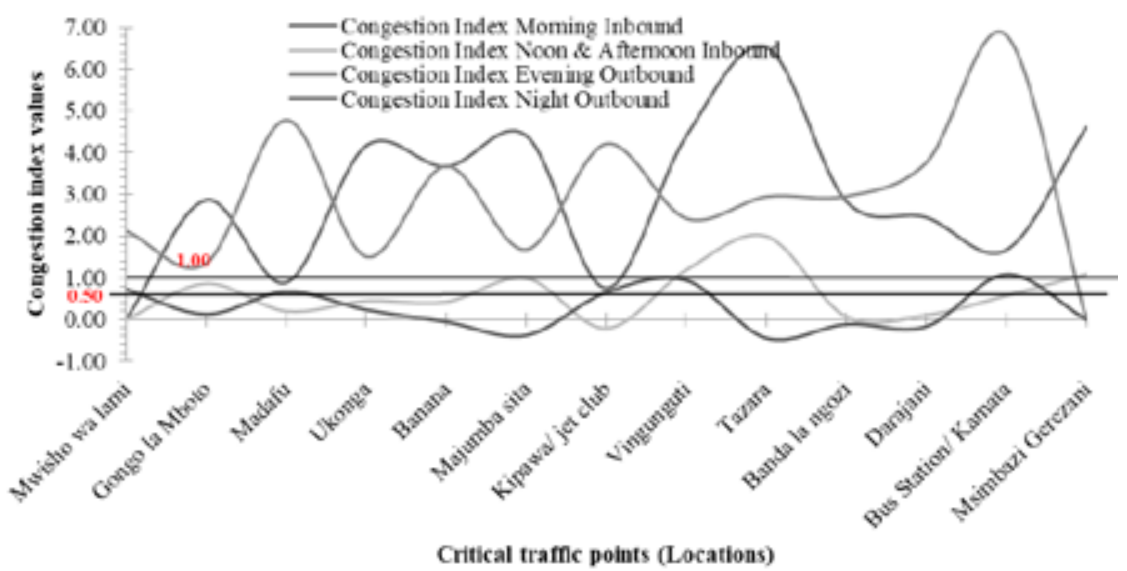

Fig. 6.

The Congestion Index ((CI) Values Distribution Along Bagamoyo Road at Various Critical Traffic Points (CTPs)) for a Given Time Slots During Inbound and Outbound Directions

For the case of congestion Index (CI) Figure 8 , the higher values ranging from 0.5 and above correspond to jam and crowded flow characteristics. From this Figure during inbound almost all CTPs indicated to have CI values above 0.50 signifying medium and high traffic flow fluctuations leading to either crowded or jam flow at various stretches of the road network. Whereas, during outbound almost the same CTPs are observed to have higher values but with slight differences as shown on the Figure 8. The CI distributions during noon and afternoon inbound and night outbound low values are shown to be indicated in most of the CTPs along Nyerere Road ranging below 0.5 signifying free flow characteristics. 
(c) TD_TI Values variations - INBOUND

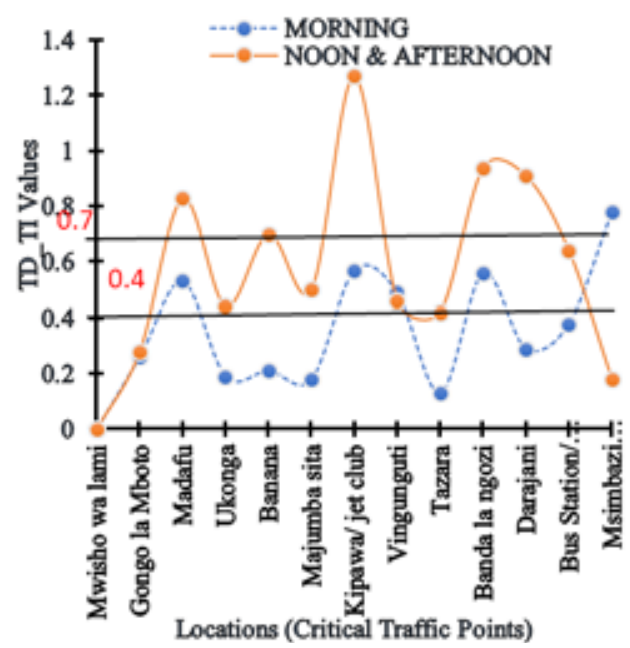

(d) TD_TI Values variations - OUTBOUND

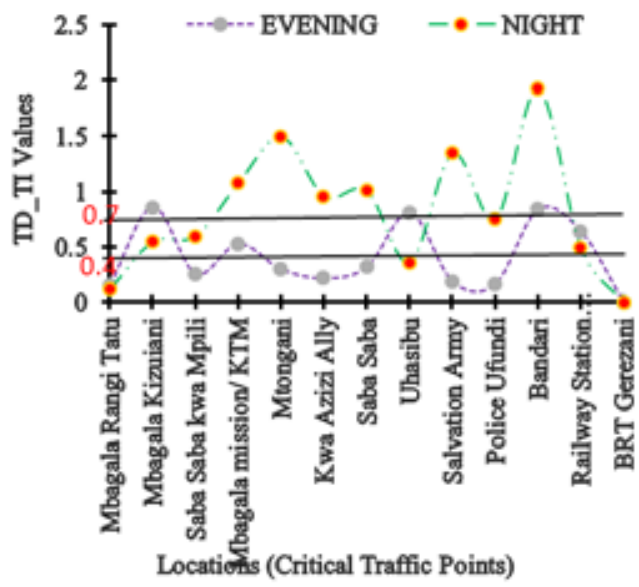

\section{Fig. 7.}

The Travel Time-Delay Transition Index ((TD_TI) Values Distributions at Various Critical Traffic Points (Ctps)) (c) Inbound Directions and ( $\bar{d})$ Outbound Directions

Note 1: Black lines (0.4 and 0.7) are drawn to represent the division of distributions.

Note 2: 0.00 -TD_TI VALUE means the starting point towards the next road link i.e the direction of travel towards the $\overline{C B D}$ and vice versa.

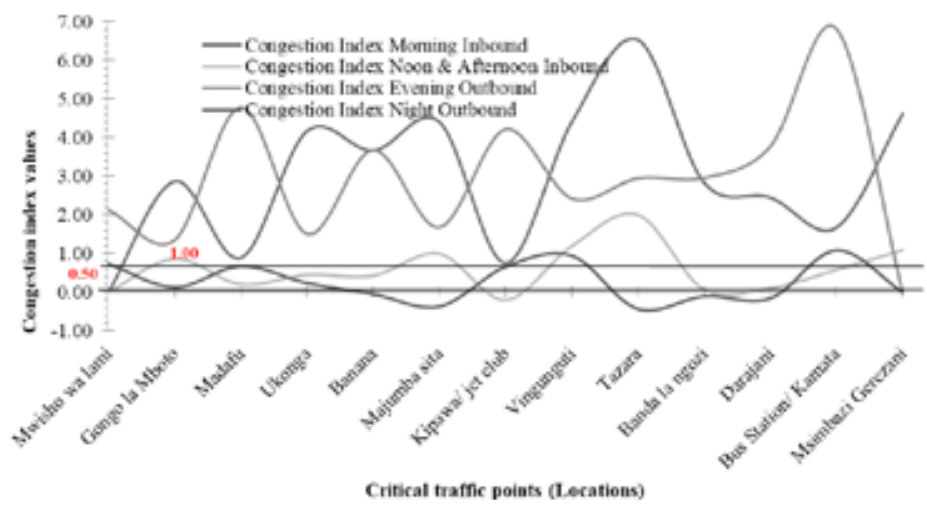

Fig. 8.

The Congestion Index ((CI) Values Distribution Along Nyerere Road at Various Critical Traffic Points (CTPs)) for a Given Time Slots During Inbound and Outbound Directions.

Note: 0.00 - CI VALUE means the starting point towards the next road link i.e the direction of travel towards the $C B D$ and vice versa.

\subsubsection{Kilwa Road}


The evaluation of the CTPs performance along Kilwa road has done by analyzing the variations of TD_TI values at each link (Figures 3 e and $\mathrm{f}$ ). From Fig $3 \mathrm{e}$ the low values (below 0.7 ) are associated to the jam and crowded vehicle flow characteristics being the result of high traffic flow pattern/ state variations at these CTPs. These CTPs are identified to be Mtongani, Kwa Azizi Ally,
Saba Saba, Salvation Army, Police Ufundi, Bandari stop, Railway stop during inbound. However, those observed to indicate high flow pattern variations (low TD_TI values below 0.7) during Outbound are the same CTPs except that their values have slight differences (Figure $3 \mathrm{f}$ ).

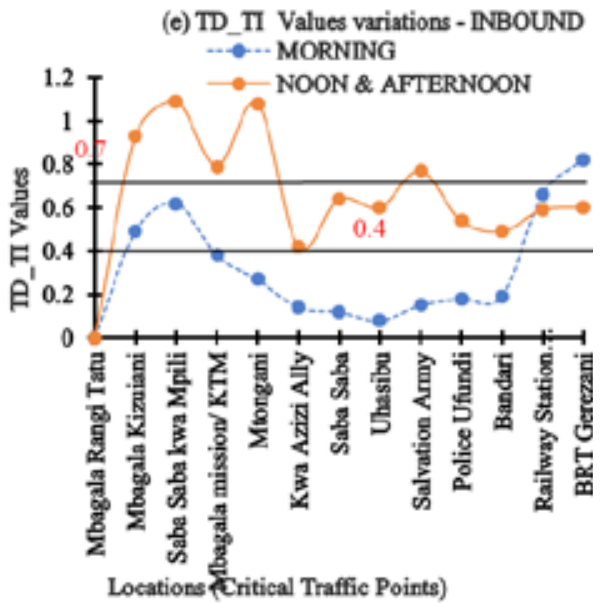

(f) TD_TI Values variations - OUTBOUND

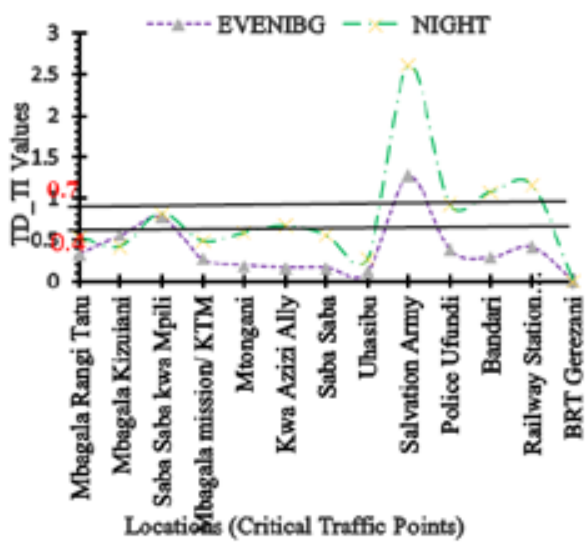

Fig. 9.

The Travel time-Delay Transition Index ((TD_TI) Values Distributions at Various Critical Traffic Points $(C T P s))(e)$ Inbound Directions and $(\bar{f})$ Outbound Directions

Note 1: Black lines (0.4 and 0.7) are drawn to represent the division of distributions.

Note 2: 0.00 -TD_TI VALUE means the starting point towards the next road link i.e the direction of travel towards the $\overline{C B D}$ and vice versa.

For the case of congestion Index (CI) distribution Figures 10, the higher values 0.5 and above correspond to jam and crowded flow characteristics. From this Figure almost all CTPs indicated to have higher CI values during inbound illustrating that most of the places during inbound (solid lines) are observed to experience either crowded or jam of different magnitude depending on the effect of the road bottleneck. Whereas, during outbound (Figure 10 - dashed lines) the CTPs observed to have higher values were identified to be Mtongani (3.85), Kwa Azizi (5.44), Saba Saba (5.11), Uhasibu (9.13), Salvation Army (2.88), Police Ufundi (3.04), Bandari (10.69) and Railway Station roundabout (4.19). The CI distributions during noon and afternoon inbound and night outbound observed to be low values (below 0.5 ) signifying for free 
flow characteristics in most of the places and time. This definite show that at that time the effects of the presence of road bottlenecks does not affect much the vehicle flow characteristics due to few numbers of vehicles on the road.

\subsection{Factors Associated with Traffic Flow Pattern Variations}

The performance characteristics of all studied road networks have been evaluated by closely considering the variations of TD_TI and CI (Figure 5 to 10). The major factors identified to be associated with the observed variations at various CTPs along all these road networks are summarized in the Table 5. The analysis of the causes of high values of low values TD_TI and high values $\mathrm{CI}$ in most of the CTPs along urban road networks are mainly due to the presence of incoming and outgoing roads (B1), bus stops (B2), T-junctions (B5), Traffic light (B4) and Road humps (B3) (Table 5).

On the other hand, these factors are responsible for lower values of TD_TI values and high CI values (Figure 3 and 4 ) signifying high degree of traffic flow pattern variations at identified points which then translate the formation of traffic congestions at the said locations.

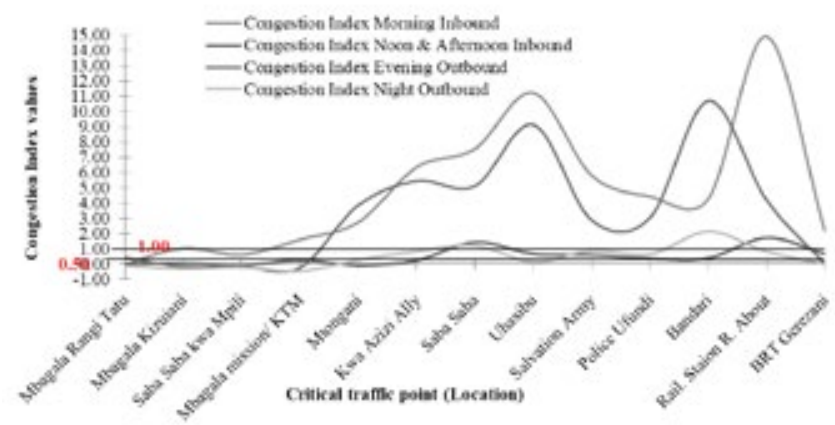

Fig. 10.

The Congestion Index ((CI) Values Distributions Along Kilwa Road at Various Critical Traffic Points (CTPs) for a Given Time Slot During Inbound and Outbound Directions.

\section{Table 5}

The Frequency of the Factors Causing Variations of Travel Time-Delay Transition Index (TD_TI) and CI at Various CTPs on Respective Road Networks (a) Inbound and (b) Outbound

\begin{tabular}{|c|c|c|c|c|c|c|c|c|c|c|c|c|c|c|c|c|c|c|c|}
\hline \multirow{2}{*}{$\begin{array}{c}\text { Road } \\
\text { Network }\end{array}$} & \multirow{2}{*}{$\begin{array}{l}\text { No of } \\
\text { CTPs }\end{array}$} & \multicolumn{9}{|c|}{ INBOUND (Towards CBD) } & \multicolumn{9}{|c|}{ OUTBOUND (From CBD) } \\
\hline & & B1 & B2 & B3 & B4 & B5 & B6 & B7 & B8 & B9 & B1 & B2 & B3 & B4 & B5 & B6 & B7 & B8 & B9 \\
\hline Bagamoyo & 14 & 19 & 20 & 1 & 12 & 9 & 0 & 3 & 0 & 0 & 16 & 19 & 0 & 8 & 7 & 0 & 4 & 0 & 0 \\
\hline Kilwa & 13 & 17 & 18 & 0 & 4 & 3 & 0 & 2 & 1 & 0 & 13 & 12 & 0 & 3 & 3 & 0 & 1 & 0 & 0 \\
\hline Nyerere & 13 & 14 & 16 & 7 & 7 & 6 & 0 & 4 & 0 & 1 & 11 & 15 & 0 & 6 & 6 & 0 & 3 & 1 & 1 \\
\hline
\end{tabular}

Notes: B1 -T-Junctions; B2 - Bus Stops; B3 - Road Humps; B4 - Traffic Lights; B5 - Cross-Junctions; B6 - Work Zones; B7 - Incidents /accidents; B8 - Road Zebra; B9 - Major New Constructions; 


\section{Discussion of Results}

\subsection{Characteristics of the Studied Road Networks}

The studied road networks comprised Critical Traffic points (CTPs) that have shown to experience large traffic flow variations resulting into slow traffic movement and at some point, lead to frequent stop and go characteristics. Most of the CTPs along all three road networks studied experiences similar traffic pattern variations except the one at Nyerere road which is heavily affected by the construction of the fly-over aimed at releasing congestion. These behaviors imply either the propagations or non-propagations of traffic congestions at different locations and time on major urban roads in Dar es Salaam city (Table 5 and Figure 3). The road networks serve as links to all street roads (collector roads) which connect different types of land use activities in the study area. Common to all, the road networks are the presence of various roadbus stops, incoming and outgoing collector roads, $\mathrm{T}$ - junctions and other features along the roads that result in road-side obstructions and thereby impeding the free movements of vehicles. Associated with these problems are the problems of narrowness and poor or no channelization of the intersecting roads to separate the traffic streams hence enabling smooth flow of main line stream and those entering or leaving the main road.

\subsection{Traffic Flow Pattern Variations}

Traffic patterns variation on urban road network is complicated and varies significantly with roads, road features on the roads such as different types of junctions with street roads (collector roads) and several other road configurations. From Figures
3 and 4 the low values of TD_TI (less or equal to 0.40 ) and high values of CI (above $0.5)$ are associated with the slow vehicle movement at the particular place and time. This phenomenon translates higher traffic patterns fluctuations leading to propagations of traffic congestion. High values of $\mathrm{TD}_{=} \mathrm{TI}$ (above 0.70 as shown in Figure 3) as well as low values of $\mathrm{CI}$ (less or equal to 0.5 ) translate to high traffic stream movement signifying free flow phenomena and thus low traffic flow pattern/state fluctuations. High traffic flow patterns variations were mostly noticed at most of the CTPs during morning inbound and evening outbound as these peak periods were observed to have a significant number of vehicles using the road network. Practically these low values indicate the very slow traffic movement leading to the stop-and-go causing the traffic jam or crowded. Whereas, during the noon and afternoon (inbound and night (outbound) several CTPs experience free flow of vehicles showing high values of TD_TI (above 0.7 as shown on the Figures 3 and 4) and thus signifying that there is less or no impedes to traffic flow.

The regular interference of T-joints roads, bus stops, cross-junctions, traffic lights and road humps to traffic flow on urban road networks, which often result in traffic bottleneck, is identified in most of the figures constructed for the studied networks as a major challenge to traffic management across urban road network in in developing cities Dar es salaam included which then resulted into the traffic congestion in most of the areas requiring urgent attention especially during the morning inbound and evening outbound. During this time slots most of the road users are either travelling towards or vice versa the $\mathrm{CBD}$ areas for office, social and other opportunities or residential areas on the peripheries. 


\subsection{Factors Associated with Traffic Flow Pattern Variations}

Traffic congestion problems are manifesting in many of the major urban centers in developing countries Tanzania inclusive. They are indeed becoming a menace to free flow of traffic in these cities. The study of congestion problems at urban road networks revealed that there are significant spatiotemporal variations in traffic flows characterized by low TD_TI (below and equal 0.70) during morning and evening peak periods as well as high values of CI (equal and above 0.50 ) which are highly characterized by crowded and jam flow phenomena. The analysis of the causes of high values of Travel time-Delay (TD) and hence low TD_TI values in most of the urban road networks are mainly due to the presence of T-junctions (B1), bus stops (B2), cross-junctions(B5), traffic light (B4) and road hump (B3) (Table 6 and Figure 3). The average frequency for all these factors on each road network is shown to be higher on Bagamoyo road (12.3) Table 6.

\section{Table 6}

Factors Leading High Frequency of Occurrence in Peak Periods During the Respective Travel Directions at Various CTPs On Respective Road Networks

\begin{tabular}{|c|c|c|c|c|c|c|c|c|c|c|}
\hline Road Network & \multicolumn{4}{|c|}{ INBOUND (Towards CBD) } & \multicolumn{3}{c|}{ OUTBOUND (From CBD) } & Average Frequency \\
\hline & B1 & B2 & B3 & B4 & B5 & B1 & B2 & B4 & B5 & \\
\hline Bagamoyo & 19 & 20 & 1 & 12 & 9 & 16 & 19 & 8 & 7 & 12.3 \\
\hline Kilwa & 17 & 18 & 0 & 4 & 3 & 13 & 12 & 3 & 3 & 8.1 \\
\hline Nyerere & 14 & 16 & 7 & 7 & 6 & 11 & 15 & 6 & 6 & 9.8 \\
\hline
\end{tabular}

Notes: B1 -T-Junctions; B2 - Bus Stops; B3 - Road Humps; B4 - Traffic Lights; B5 - Cross-Junctions;

From these arguments, Bagamoyo road network is said to exhibit significant values of the factors that cause traffic flow impedes leaving aside Nyerere road whose traffic congestion has been reduced by the recently constructed flyover at the Tazara junction, hence its selection for further flow parameter measurements at all particular places and time indicating low and medium values of Travel time-Delay Transition Index (TD_TI) as well as high values of $\mathrm{CI}$ (equal and above 0.50 ) for determining the important inputs of the traffic flow model to be developed for prediction of the real situation of traffic flow characteristics.

\section{Conclusion}

This study has brought into focus the use of travel time-delay data converted to transition and congestion indexes to reveal critical traffic points on the road network that indicate to have high or low traffic state/ patterns variation at particular time. These traffic flow pattern variations are responsible to directly influence vehicle speed and smooth traffic flow at a particular place and time. The main causes of these variations and thus translating to the formations of congestion have been indicated to be the incoming and outgoing roads which act as the collector-distributor roads into the main urban road and vice versa, bus stops, cross -junctions, T-junctions and road humps. These factors are considered to be static ones acting as the bottlenecks / impedes to the vehicle flow and thus resulting into slow vehicle movement at several locations at particular time forming vehicles queues.

This study results reveal that travel time-delay data are used to identify various roadside 
friction points that impact the speed of the vehicle on some of the urban road networks translating to either free flow, crowded or jam flow and consequently be able to study the traffic congestion mitigation processes by understanding their main causes.

\section{Acknowledgements}

The authors would like to acknowledge the financial support given by the National Institute of Transport, Government of Tanzania (the employer of the corresponding author) for carrying out the field data collection.

\section{References}

Ataiwe, T.N.; Salman, N.D.; Ismael, H.S. 2012. Identify Traffic Congestion Using Speed Data Measured by GIS, GPS Technique, Iraqi Journal of Science 53(5): 1156-1161.

Chauhan, D. K. V.; Kansagra, M. K. J.; Prajapati, V. K. 2017. Review on Estimation of L.O.S through Congestion on Urban Road - A Case Study of Vrundavan Chowkdi - Vadodara City, International Journal of Advance Engineering and Research Development Special Issue SIEICON-2017: 1-4.

Deardoff, M. D.; Wiesner, B. N.; Fazio, J. 2011. Estimating free-flow speed from posted speed limit signs, Procedia-Social and Behavioral Sciences, 16: 306-31.

Fazio, J.; Wiesner, B.N.; Deardoff, M.D. 2014. Estimation of free-flow speed, KSCE Journal of Civil Engineering 18(2): 646-650.

He, F.; Yan, X.; Liu, Y.; Ma, L. 2016. A traffic congestion assessment method for urban road networks based on speed performance index, Procedia engineering 137: 425-433.

Karuppanagounder, K.; Muneera, C.P. 2017. Performance Evaluation of Urban Links under Heterogeneous Traffic Condition, European Transport - Trasporti Europei, 65: 1-10.
Kiunsi, R.B. 2013. A review of traffic congestion in Dar es Salaam city from the physical planning perspective, Journal of Sustainable Development 6(2): 94-103.

Kumar, S.V.; Sivanandan, R. 2017. Traffic Congestion Quantification for Urban Heterogeneous Traffic Using Public Transit Buses as Probes, Periodica Polytechnica Transportation Engineering (in print). doi: https://doi. org/10.3311/PPtr.9218.

Lamotte, R.; Geroliminis, N. 2017. The morning commute in urban areas with heterogeneous trip lengths, Transportation research procedia 23: 591-611.

Lu, C. 2017. Estimate freeway travel time reliability under recurring and nonrecurring congestion. Graduate Theses and Dissertations, 16170. Iowa State University, USA.

Rao, M.A.; Rao, K.R. 2016. Identification of traffic congestion on urban arterials for heterogeneous traffic, Transport Problems 11(3): 131-143.

Torrisi, V.; Ignaccolo; M.; Inturri, G. 2017.Estimating travel time reliability in urban areas through a dynamic simulation model Transportation Research Procedia, 27: 857-864.

Wang, L.; Chen, H.; Li, Y. 2014. Transition characteristic analysis of traffic evolution process for urban traffic network, The Scientific World Journal, 2014(ID 603274): 1-9. doi: https://doi.org/10.1155/2014/603274.

Wen, H.; Sun, J.; Zhang, X. 2014. Study on traffic congestion patterns of large city in China taking Beijing as an example, Procedia-Social and Behavioral Sciences 138: 482-491.

Xu, C.; Li, Z.; Wang, W. 2016. Short-term traffic flow prediction using a methodology based on autoregressive integrated moving average and genetic programming, Transport 31(3): 343-358.

Zhang, K.; Sun, D.; Shen, S.; Zhu, Y. 2017. Analyzing spatiotemporal congestion pattern on urban roads based on taxi GPS data, Journal of Transport and Land Use 10(1): 675-694. 